\title{
Investigation of Structural, Topographic and Optical Properties of Triangular Nanostructured Tin Dioxide Films
}

\author{
Paramita Sarkar $^{1}$, S. K. Tripathy ${ }^{1, *}$, and K. L. Baishnab ${ }^{1}$ \\ ${ }^{1}$ Department of Electronics and Communication Engineering, National Institute of Technology Silchar, \\ Assam-788010, India.
}

\begin{abstract}
.
In this paper, we have investigated the structural, topographic and optical properties of tin (IV) dioxide $\left(\mathrm{SnO}_{2}\right)$ films grown onto glass substrates using controlled aqueous growth method. The characterization of $\mathrm{SnO}_{2}$ films are carried out with the help of X-ray Diffractometer (XRD), DRS UV-Vis-NIR spectroscopy, Atomic Force Microscope (AFM). The XRD pattern reveals that $\mathrm{SnO}_{2}$ films have been crystalline with cassiterite tetragonal structure with an average grain size of $27.7 \mathrm{~nm}$. Further, UV-Vis-NIR spectroscopy data displays the increasing nature of transmittance in the visible as well as in near-infrared regions. The estimated optical bandgap is found to be $3.89 \mathrm{eV}$ and direct in nature. We have also obtained the topographic image of $\mathrm{SnO}_{2}$ films using atomic force microscope (AFM). Topography images confirm the formation of crystals and the images indicates that the layered triangular nanostructures with large surface area has been formed on glass substrates. All the above-obtained parameters are compared with available data and found in good agreement.
\end{abstract}

Keywords: Metal Oxides; Experimental Techniques; Nanostructures; TCOs 


\section{Introduction}

The well-defined and oriented hierarchical nanostructures such as nanorods, nanowires, nanosheets and nanotubes are the basic building blocks of several smart devices. The low cost and large-scale production of these nanomaterials are the crucial challenges in the field of nanotechnology. Besides the morphological structures, other properties such as optical, electronic, electrical and stability of the materials are also important in technological point of view. $\mathrm{SnO}_{2}$ is an inorganic n-type metal oxide which is having a semiconducting property with large band-gap of 3.6-3.96 eV [Wang et al., 2013]. The conductivity of $\mathrm{SnO}_{2}$ films essentially depends on the oxygen vacancies, more the vacancies more the quality weakening of thin films [Huang et al., 2010]. $\mathrm{SnO}_{2}$ is a smart material which is widely used for numerous applications such as supercapacitors, photocatalysts, batteries, transparent conducting oxides (TCO), lightemitting devices etc. [Liu et al., 2014]. $\mathrm{SnO}_{2}$ thin films have been synthesized by following different methods such as sol-gel method [Diana et al., 2010], chemical vapour deposition [Liu et al., 2005], sputtering [Lee et al., 2011], controlled aqueous growth [Vayssieres and Graetzel, 2004], laser ablation [Liu et al., 2003], spray pyrolysis [Joseph et al., 2009], spin coating [Lee et al., 2013] etc. in addition to this controlled aqueous growth is also an efficient technique for thin film deposition. Compared to any other techniques, this method provides a cost-effective way to produce good quality thin films. In consideration of today's energy demand, TCOs are playing a major role in solar cell development. There is always a need for good chemical stability and mechanical hardness for TCOs in solar cell manufacturing. The current industrial trend is indium tin oxide (ITO) as promising TCO for its excellent optical and electrical properties, but high processing cost is the main disadvantage [Kim et al., 1999]. Transparency of $\mathrm{SnO}_{2}$ thin films is high in the visible spectrum of light and also potential candidate for the fabrication of TCOs and infrared reflectors. It is a favourable material for optoelectronic devices as it shows promising photo stability, high mechanical strength, possess good chemical stability and excellent carrier mobility with least toxicity [Seo et al., 2016].

In this work, we have prepared $\mathrm{SnO}_{2}$ thin films onto glass substrates using controlled aqueous growth at low cost and low temperature. These films are further investigated in terms of their structural, optical and topographic features. This paper is arranged as follows. Section 2 explains the materials and methodology involved in this work. Section 3 projects results and discussion and section 4 concludes the whole work.

\section{Materials and Method}

Stannic chloride pentahydrate (Central Drug House Pvt. Limited, 97.5\%), urea (Thomas Beaker, 99.5\%), hydrochloric acid (S.D. Fine, 35\%), acetone (S.D.Fine, 99.5\%), ethanol (Changshu Yangyuan Chemical China, 99.9\%) and MilliQ water (18.2 M $\Omega \mathrm{cm}$ ) have been used as received, without any further purification. All glasswares are cleaned with detergent, $\mathrm{HCl}$ solution, rinsed with MilliQ water, ethanol and dried in an oven before use. $\mathrm{SnO}_{2}$ thin films are deposited onto a pre-cleaned glass substrate. The cleaning procedure of glass substrates follows the sonication with diluted $\mathrm{HCl}$, rinsed with ethanol, acetone, MilliQ water and desiccated in hot air oven before use. The synthesis has been performed using $100 \mathrm{~mL}$ (MilliQ water) solution containing of $0.09 \mathrm{mM}$ of $\mathrm{SnCl}_{4} .5 \mathrm{H}_{2} \mathrm{O}$ as metal ion precursor and $0.015 \mathrm{M}$ of $\left(\mathrm{NH}_{2}\right)_{2} \mathrm{CO}$ as structure directing agent. $5 \mathrm{~mL}$ of fuming $\mathrm{HCl}(34.5 \%)$ is added to the solution to make $\mathrm{SnCl}_{4} .5 \mathrm{H}_{2} \mathrm{O}$ freely soluble in water. The solution is kept in a borosilicate conical flask and inside the flask rigorously cleaned glass substrate has been placed standing against the wall. The conical flask is tightly closed and kept in a regulatory oven for 48 hours at a temperature of 
$95^{\circ} \mathrm{C}$. After 48 hours, the film is rinsed with MilliQ water to avoid any contamination, dried at room temperature and preserved in a clean environment. The $\mathrm{SnO}_{2}$ thin films are deposited following the method of Vayssieres et al. [7] with modification in experimental setup as shown in Fig. 1(a).

\section{Results and Discussion}

There is a number of methods to prepare $\mathrm{SnO}_{2}$ films as discussed in the introduction. The different method gives different particle size, optical band-gap, morphology, different stability of phases. Properties of the films vary depending on the type of substrate, solvent, metal ion precursor, operating temperature, $\mathrm{pH}$ of the aqueous solution etc. Choice of methodology depends on the application of the film as well. In this work, the formation of the film is in situ operation. The main reactions for the growth mechanism of $\mathrm{SnO}_{2}$ films are illustrated in the following equations:

$$
\mathrm{CO}(\mathrm{NH})+\mathrm{HO}=2 \mathrm{NH}+\mathrm{CO}_{22} \quad 3 \quad 3
$$

$$
4 \mathrm{NH}+\mathrm{H} \mathrm{O}=4 \mathrm{NH} \mathrm{OH}_{32}
$$

$$
4 \mathrm{NH} \mathrm{OH}+\mathrm{SnCl}=\mathrm{Sn}(\mathrm{OH})+4 \mathrm{NH} \mathrm{Cl}_{4} \quad 4 \quad 4 \quad 4 \quad 4
$$

$$
2 \mathrm{Sn}(\mathrm{OH})=2 \mathrm{SnO}+4 \mathrm{H} \mathrm{O}_{4} 2
$$

Eq. (1) is urea hydrolysis; it decomposes into ammonia and carbon dioxide. Urea is a very weak basic and easily soluble in water. Urea hydrolysis takes place at $90-100^{\circ} \mathrm{C}$. In the presence of water, ammonia will form ammonium hydroxide. The hydrated metal ions will further react with ammonium hydroxide and the formation of tin hydroxide will occur, which will further decompose into $\mathrm{SnO}_{2}$. By this method, hydrolysis of urea and condensation of hydrated metal ion will take place, and $\mathrm{SnO}_{2}$ film will be deposited onto the glass substrate. X-ray diffraction measurements have been done to measure crystallographic structure, dvalues, lattice parameters, grain size, texture coefficient and crystal phase. For X-ray diffraction measurement, $\omega / 2 \theta$ scans are used ranging from 10 to $80^{\circ} \mathrm{C}$, it employees $\mathrm{Cu}-\mathrm{K} \alpha$ radiation source $(\lambda=0.15406$ $\mathrm{nm}, 40 \mathrm{kV}, 30 \mathrm{~mA}$ ). The obtained XRD peaks are matching with the standard data of the joint committee on powder diffraction standards (JCPDS) data file with card no \#00-041-1445. Fig. 1(b) depicts the examined XRD pattern, it exhibits clear diffraction peaks which indicate the single-phased crystalline $\mathrm{SnO}_{2}$ film. All the observed peaks are indexed to tetragonal rutile structure of $\mathrm{SnO}_{2}$, except $\mathrm{SnO}_{2}$ no other diffraction peaks were detected in the XRD pattern. It confirms that the films are well crystalline and presence of only $\mathrm{SnO}_{2}$ without any impurities. The pattern shows the diffraction peaks indexed to (110), (101), (211), (200), (002), (112), (220), (310) planes and major peak is along (110) plane is c axis oriented. The calculated lattice parameters $\mathrm{a}=\mathrm{b}$ and $\mathrm{c}$ are equal to 4.794 and $3.178 \mathrm{~A}^{\circ}$, respectively. The (c/a) ratio is belonging to the preferred oriented plane (110), which is found in good conformity with JCPDS (\#00-041$1445)$ value. The obtained lattice parameters are analogous to the other reported works [Liu et al., 2005; Liu et al., 2003]. Calculated grain size is $27.7 \mathrm{~nm}$ and comparable with the literature [Lee et al., 2011]. Lattice strain is nothing but the distribution of lattice constants arise from the 
crystal imperfections like dislocation of the lattice. The estimated lattice strain for this work is 0.018232 . Lesser the value of lattice strain means lesser crystal imperfection and distortion.

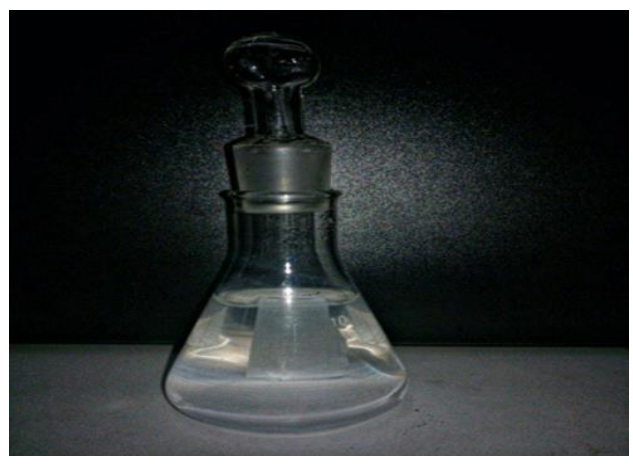

(a)

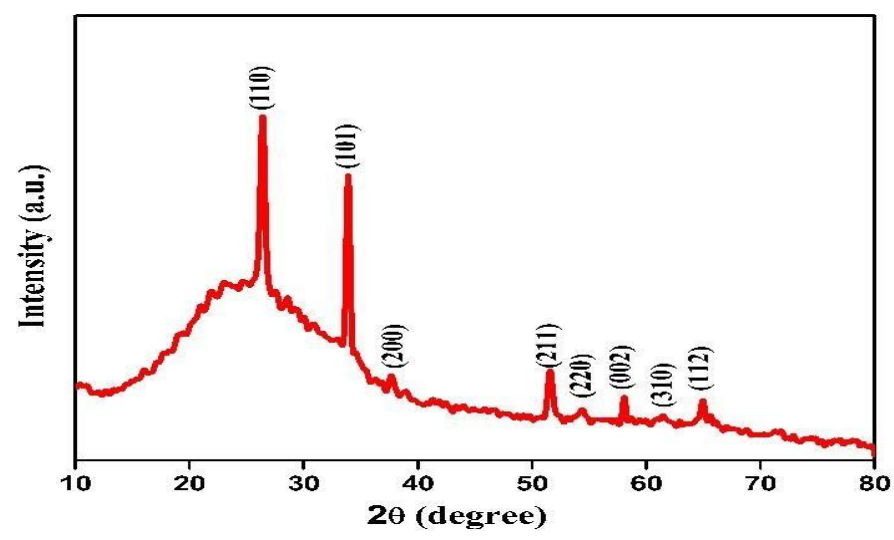

(b)

Figure 1 (a) Borosilicate conical flask setup along with substrate after deposition of the film. (b) XRD pattern of synthesized $\mathrm{SnO}_{2}$ film.

Optical properties have been studied using diffuse reflectance UV-Vis-NIR spectrometer. The absorbance, transmittance and reflectance spectrums are measured in the range from $2002500 \mathrm{~nm}$. As a TCO material, it is necessary to have an excellent optical transmittance. Fig. 2(a) and 2(b) shows the percentage transmittance curve and bandgap of the $\mathrm{SnO}_{2}$ film. There is a sharp increase in transmittance $(\%)$ with increasing wavelength $(\mathrm{nm})$, it is showing almost $80 \%$ transmittance in NIR (near infrared) region. A good TCO material is not absorbing light in the visible range. In this work, fabricated thin films have shown minimal absorbance 0.2 a.u, in the visible region. It is attaining the value of 0.1 a.u. in near infrared region (NIR). The electron transition from valance band to the conduction band by absorption of photon energy can be either direct or indirect. Using Tauc's plot, optical band-gap is estimated. It follows the Eq. (5):

\section{$\square \square\left(\square_{-n} \square A h E \square \quad \square_{g} \square \quad\right.$ (5) where, h, $\gamma, \mathrm{A}, \alpha$, and}

Eg are called Plank's constant, incident light frequency, constant depending on transition, absorption coefficient, and optical bandgap, respectively. Again, $n=1 / 2,2,3$, and 3/2 for indirect, direct, forbidden indirect, forbidden direct electronic transition. To estimate the optical band-gap, ( $\alpha$ hv) 2 versus (hv) graph has been plotted, and slope taken from the graph gives the bandgap of the films in $\mathrm{eV}$. In this study, $\mathrm{SnO}_{2}$ films attained the bandgap of $3.89 \mathrm{eV}$. The values are comparable with the other reported literature [Diana et al. 2010; Liu et al., 2005]. Further, the surface topographic study of the film is done by using AFM. The repetitive measurements from more than one film demonstrate that $\mathrm{SnO}_{2}$ forms the triangle shaped atomic layer on glass substrates. Fig. 3 represents the AFM study of the $\mathrm{SnO}_{2}$ thin film under different scanning area. Topography images confirm the formation of crystals. The contrast difference in the images indicates that the layered structure has been formed on glass substrates. From electronic device and applications point of view, triangular nanostructures provide the largest area for any 2D material. It is well established for black phosphorus thin films that the triangular nanostructures are energetically most favourable facet according to the experimental as well as the theoretical study [Seo et al. 2016]. 


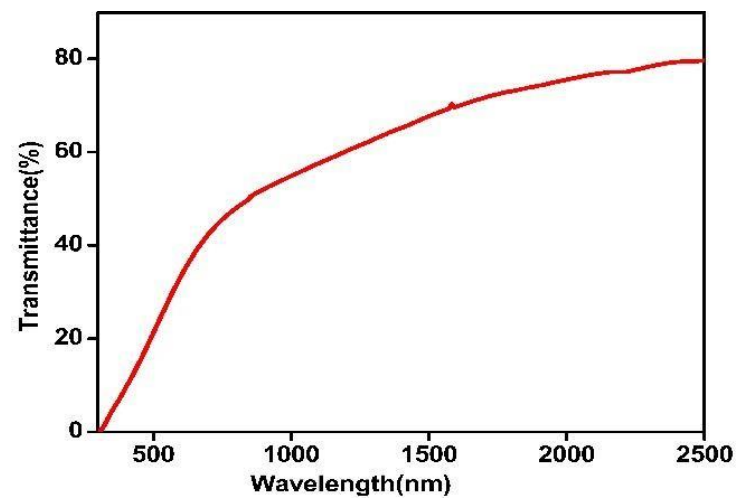

(a)

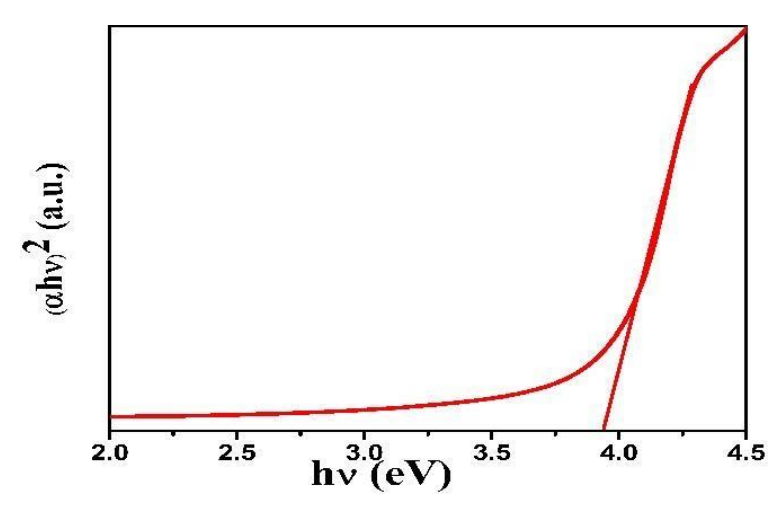

(b)

Figure 2. (a) \%Transmittance versus wavelength (nm) (b) Bandgap versus hv (eV) curve of $\mathrm{SnO}_{2}$ film.

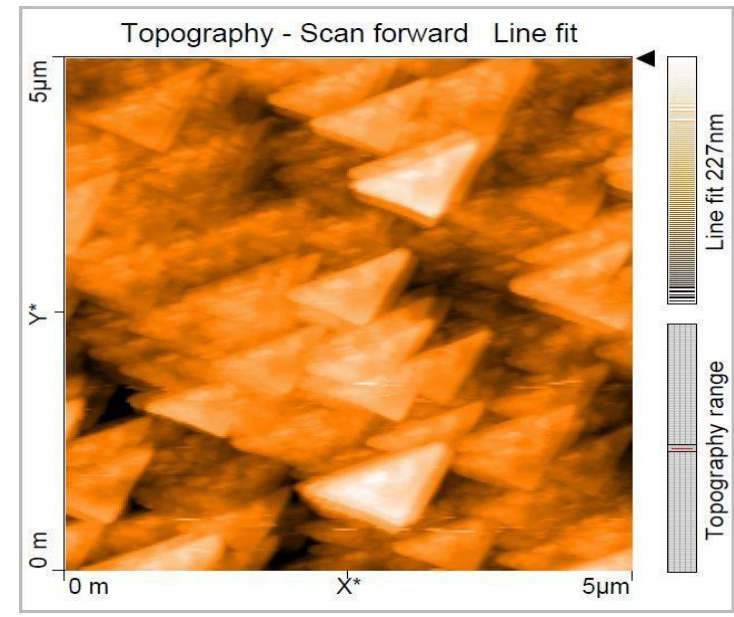

(a)

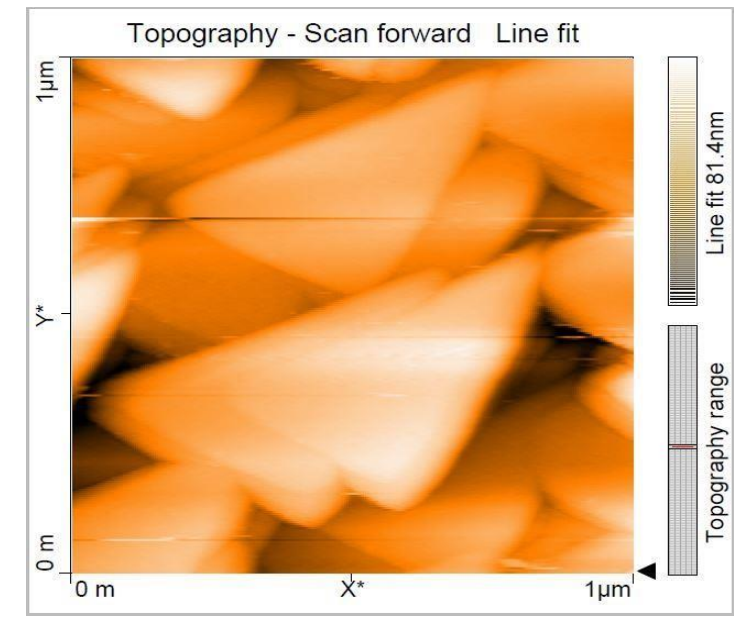

(b)

Figure 3. AFM image of triangle shaped atomic layers of $\mathrm{SnO}_{2}$ film (a) $(5 \mu \mathrm{m} \times 5 \mu \mathrm{m})(\mathrm{b})(1 \mu \mathrm{m} \times 1 \mu \mathrm{m})$.

\section{Conclusion}

The films grown on the glass substrates are tetragonal rutile structure of $\mathrm{SnO}_{2}$, they are well crystalline and oriented. XRD confirms the average crystallite size of $27.7 \mathrm{~nm}$. The optical study reveals that films are highly transparent in visible region as well as in the near infrared region, and the estimated bandgap is $3.89 \mathrm{eV}$. The slightly higher bandgap for the films is due to the presence of excess oxygen in the $\mathrm{SnO}_{2}$ films. We have also obtained the triangular shapes on topographic images of the films. It is found that the substrate can also play a crucial role in the morphology of the films. We believe that the triangular shapes on the surface of $\mathrm{SnO}_{2}$ films prepared by controlled aqueous growth methodology are not reported yet. 


\section{Acknowledgment}

This work is funded by Early Career Research scheme (File no. ECR/2016/001404) under SERB, New Delhi, Government of India. The authors acknowledge the support provided by the Centre for Nanotechnology Research (CNR) at VIT University, Vellore supported by Nano Science and Technology Initiative (NSTI), Department of Science and Technology (DST), Government of India, New Delhi. The authors are also thankful to Prof. Sivaji Bandyopadhyay, Director, National Institute of Technology, Silchar for his continuous support in conducting this work. 


\section{References}

[1] Wang, C. M., Huang, C. C., Kuo, J. C. and Huang, J. L (2013). "Investigation of pulsed ultraviolet laser annealing of $\mathrm{Sb} / \mathrm{SnO}_{2}$ thin films on the structural, optical and electrical properties," Surf. Coat. Technol., Vol. 231, pp. 374-379.

[2] Huang, Y., Li, G., Feng, J. and Jhang, Q. (2010). "Investigation on structural, electrical and optical properties of tungsten-doped tin oxide thin films," Thin Solid Films, Vol. 518, pp. 1892-1896.

[3] Liu, Y., Jiao, Y., Zhang, Z., Qu, F., Umar, A. and Wu, X. (2014). "Hierarchical $\mathrm{SnO}_{2}$ nanostructures made of intermingled ultrathin nanosheets for environmental remediation, smart gas sensor, and supercapacitor applications," ACS Appl. Mater. Interfaces, Vol. 6, pp. 2174-2184.

[4] Diana, T., Devi, K. N. and Sarma, H. N. (2010). "On the optical properties of $\mathrm{SnO}_{2}$ thin films prepared by sol-gel method,” Indian J. Phys., Vol. 84, pp. 687-691

[5] Liu, Y., Koep, E. and Liu, M. (2005). "A highly sensitive and fast-responding $\mathrm{SnO}_{2}$ sensor fabricated by combustion chemical vapor deposition," Chem. Mater., Vol. 17, pp. 39974000.

[6] Lee, S. U., Boo, J. H. and Hong, B. (2011). "Structural, electrical, and optical properties of $\mathrm{SnO}_{2}$ : Sb films prepared on flexible substrate at room temperature," Jpn. J. Appl. Phys., Vol. 50, pp. 01AB10 (1-5).

[7] Vayssieres, L. and Graetzel, M. (2004). "Highly ordered $\mathrm{SnO}_{2}$ nanorod arrays from controlled aqueous growth," Angew. Chem., Vol. 43, pp. 3752-3756.

[8] Liu, Z., Zhang, D., Han, S., Li, C., Tang, T., Jin, W., Liu, X., Lei, B. and Zhou, C. (2003). "Laser ablation synthesis and electron transport studies of tin oxide nanowires," Adv. Mater., Vol. 15, pp. 1754-1757.

[9] Joseph, D.P., Renugambal, P., Saravanan, M., Raja, S.P. and Venkateswaran, C. (2009). "Effect of Li doping on the structural, optical and electrical properties of spray deposited $\mathrm{SnO}_{2}$ thin films," Thin Solid Films, Vol. 517, pp. 6129-6136.

[10] Lee, S. H., Hoffman, D. M., Jacobson, A. J. and Lee, T. R. (2013). "Transparent homogeneous Tin Oxide $\left(\mathrm{SnO}_{2}\right)$ thin films containing $\mathrm{SnO}_{2}$-coated gold nanoparticles," Chem. Mater., Vol. 25, pp. 4697-4702.

[11] Kim, H., Piqué, A., SHorwitz, J., Mattoussi, H., Murata, H., Kafafi, Z. H. and Chrisey, D. B. (1999). "Indium tin oxide thin films for organic light-emitting devices," Appl. Phys. Lett., Vol. 74, pp. 3444-3446.

[12] Seo, S., Lee, H. U., Lee, S. C., Kim, Y., Kim, H., Bang, J. and Lee, J. (2016). “Triangular black phosphorus atomic layers by liquid exfoliation,” Sci. Rep., Vol. 6, pp. 23736 (1-8). 